Chultem Dugarjav ${ }^{1}$, Peter D. Gunin ${ }^{2 *}$, Sergey N. Bazha ${ }^{3}$, and Mijidorj Saandar ${ }^{4}$

${ }^{1}$ Laboratory of Forestry, Institute of Botany, Mongolian Academy of Sciences

210351, Jukovin gudamj, 77. Ulaanbaatar, Mongolia,

telephone/ fax: (+976)-11-451-837; E-mail: ibot@mongol.net

$2^{*}$ Laboratory of Arid Territories Ecology, A.N. Severtsov Institute of Ecology and Evolution, RAS, 119071, Leninsky prospect, 33, Moscow, Russia,

telephone: (+7-499)-124-3313; fax: (+7-499)-124-7934; E-mail: monexp@mail.ru

(Corresponding Author);

8

${ }^{3}$ Laboratory of Arid Territories Ecology, A.N. Severtsov Institute of Ecology and Evolution, RAS, 119071, Leninsky prospect, 33, Moscow, Russia,

telephone: (+7-499)-124-3313; fax: (+7-499)-124-7934; E-mail: sbazha@inbox.ru

${ }^{4}$ MonMAP Engineering Service Co., LTD, 210232, Seoul Street, Sarora h., office 2.

Ulaanbaatar, Mongolia telephone/ fax: (+976)-11-327-824;

E-mail: msaandar@mongol.net

\title{
ECOSYSTEM APPROACH FOR EVALUATING DEGRADATION PROCESSES AND NATURE PROTECTION IN INNER ASIA
}

\begin{abstract}
The paper presents results of eco-biological assessment of Inner Asian ecosystems using the example of Mongolia as a case study. The comprehensive environmental analysis of changes in Mongolia's environment included approaches based on three principles: (1) formal, (2) administrative division, and (3) landscape-ecological. We analyzed ecosystems that have undergone at last three levels of alterations (moderate, heavy, and very heavy) due to anthropogenic factors. Based on our analysis of degradation processes that result in heavy and very heavy anthropogenic alteration of the natural environment, we isolated 5 groups of hazardous degradation processes: (1) rangeland overgrowth with shrubs, (2) deforestation of forest-steppe ecosystems, (3) desertification of ecosystems on light soils, (4) depletion of ecosystems of hydromorphic landscapes, and (5) narcotization of agrocenoses in modified
\end{abstract}

ecosystems. The comprehensive assessment of adverse changes of natural habitats has enabled a revision of the state policy for the organization of the optimum network of wildlife reserves for conservation of floristic and faunistic diversity.

KEY WORDS: Inner Asia, Mongolia, ecosystem biodiversity, land degradation nature protection, degradation processes, ecosystem conservation

\section{INTRODUCTION}

Ecological problems both on the global and regional levels arising worldwide and the necessity of their preservation demand decisions based on the knowledge of protective and self-control mechanisms of individual ecosystems (such as vegetation, soils, and fauna), of ecosystems as a whole system, and of the threshold limits of their resistance to human impact. 
Leading international organizations (UNEP, UNDP, World Meteorological Organization, World Health Organization, IUCN, etc.) have already started a transition from supporting specialized programs on the rational use of different components of natural resources to the development of comprehensive global programs, such as, for example, programs on biodiversity conservation and on control of desertification. One of the latest international documents that specifically address conservation of ecologically congenial conditions for humans and biota is The Millennium Declaration approved by more than 200 countries. This document stresses the general responsibility of nations to respect for nature. It states, "The present unresisting development models should be changed in the interest of our future welfare and well-being of our descendants".

The drylands of Asia occupy 11930119 km, from which $25,49 \%$ belong to semiarid lands, $61,14 \%$ - to arid lands, and 10,01\% to extra-arid lands. About $70 \%$ of these area have been affected by desertification. The United Nations Convention to Combat
Desertification (UNCCD) adopted in 1994, defines desertification as "land degradation in arid, semi-arid, and dry sub-humid areas resulting from various factors, including climate change and human activity".

\section{BIOGEOGRAPHICAL FEATURES OF INNER ASIA AND MONGOLIA}

Inner Asia, as well as other regions of Asia, has faced serious ecological threats at the end of the 90s of the 20th century. According to the assessments of $\mathrm{N}$. Kharin \& R. Tateishi [2000], by the beginning of the 21 st century, more than $50 \%$ of the region has been under intense or very intense disturbance. By now, a considerable area of Inner Asia requires urgent measures for ecosystem rehabilitation.

Inner Asia is a region that consists of a system of midland basins. This system includes completely drainless lacustrine basins (the Big Lakes Pane in Mongolia), basins of lakes in the Peoples' Republic of China (Ebii-Nor, Bagrashkel, Lop-Nor, Koko-Nor, GashuunNor), lakes of the Tsajdam Hollow and the

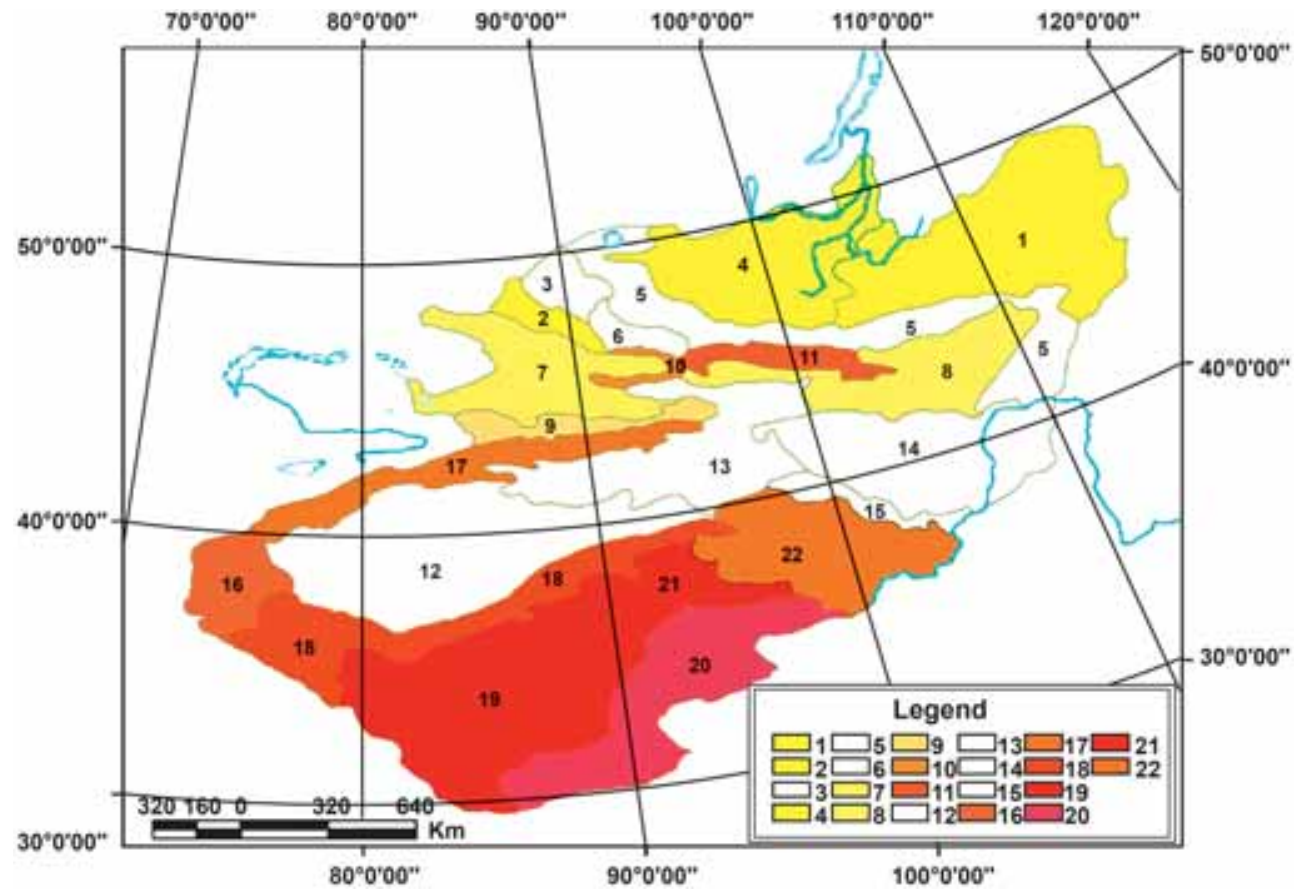

Figure 1. Inner Asia's nature zoning (by Rachkovskaya et al., 2007). 
Table 1. The main nature regions of Inner Asia

\begin{tabular}{|c|c|c|}
\hline Natural Zone & Relief & Region \\
\hline \multirow{4}{*}{ Steppe } & Plain & 1. Mongolian \\
\hline & \multirow{3}{*}{ Mountain } & 2. North-Western Mongol-Altai \\
\hline & & 3. Northern Mongol-Altai \\
\hline & & 4. Khangai \\
\hline \multirow{2}{*}{ Semi desert } & Plain & 5. Sub-Gobi \\
\hline & Mountain & 6. Central Mongol-Altai \\
\hline \multirow{5}{*}{ Desert, moderately cold } & \multirow{2}{*}{ Plain } & 7. Dzhungarian \\
\hline & & 8. Northern Gobi \\
\hline & \multirow{3}{*}{ Mountain } & 9. Northern-East Tyan-Shan \\
\hline & & 10. Mountain Dzhungarian \\
\hline & & 11. Southern-Mongol-Gobi-Altai \\
\hline \multirow{11}{*}{ Desert, moderately warm } & \multirow{4}{*}{ Plain } & 12. Kashgarian \\
\hline & & 13. Beishanian \\
\hline & & 14. Alashan-Ordoss \\
\hline & & 15. Korydor Hesi \\
\hline & \multirow{7}{*}{ Mountain } & 16. Pamir \\
\hline & & 17. South-Eastern Tyan-Shanian \\
\hline & & 18. Kun-Lunian \\
\hline & & 19. Tibet \\
\hline & & 20. Eastern-Tibet \\
\hline & & 21. Tsaidamian \\
\hline & & 22. Nan-Shanian \\
\hline
\end{tabular}

northwest part of the Tibetan Plateau, and the basins with a particulate oceanic runoff (Lake Baikal, Bujr-Nur Lake, and Dalai Nor Lake) [Gunin et al., 1998; Gunin, Bazha, 2004].

The following main ecosystems comprise the ecological portrait of Inner Asia:

- steppes with a dominance of Stipa krylovii, Cleistogenes squarrosa, and Caragana shrubs;

- semidesert with a dominance of Stipa gobica, S. glareosa, Allium polyrhizum, A. mongolicum;
- various dwarf semi-shrub and shrub deserts;

- extremely arid deserts.

The functioning of these ecosystems is limited by the maximum of summer atmospheric precipitation due to the East-Asian monsoon and by the minimum of winter temperature associated with the Siberian anticyclone. These two primary features define the extreme ecological conditions in the region.

The most arid types of ecosystems are in the mountains: mountain desert, semi desert, and steppe (including high-mountain 
cryophilic steppe). Overall, in Inner Asia, there are 8 plain and 14 mountain provinces (See Figure 1; Table 1) [Rachkovskaya et al., 2005].

The anthropogenic impact alters natural processes eventually causing a "mutation" of ecosystems. Ecosystems existing under severe ecological conditions require special attention at all stages of management: investigation, use, and protection. They demand the development of ecologically sound interaction principles unified by a specially developed concept for nature management, including systems that combat desertification and promote ecosystem conservation in landscapes under severe ecological conditions. Such systems and approaches require the creation of territorial models based on key plots and they may have a significant methodological value.

\section{METHODOLOGICAL APPROACHES}

The assessment of comprehensive environmental investigation of changes in Mongolia's environment included approaches based on three principles: (1) formal, (2) administrative division, and (3) landscape-ecological. In the first approach, the boundaries of topographic divisions or grids serve as the study objects. The second approach is used when the objects of assessment are units of the region's political and administrative divisions. The third approach is applied when the main goal of assessment is an attempt to differentiate the biosphere into small and/or large scale mapping units (e.g., ecosystem types).

Landscape-ecological studies in Mongolia have been effective in cases where the soils and vegetation have been well studied and when specialized and integrated maps of the regions have already been available. The availability of such maps for Mongolia [Ecosystems of Mongolia, 1995] made it possible to use the landscapeecological mapping units to determine spatial differentiation of the soils and vegetation and to define ecosystem conditions corresponding to elementary, local, or landscape levels of chorological classification of their structure [see, e.g., Vinogradov 1984; Vostokova et al., 1995]. In this study, we used the same method as was utilized in the compilation of the map Ecosystems of Mongolia [Gunin et al., 1995] where mesoecosystems represented basic level of units of the map. This approach provided for a much better inventory of the ecosystems and their classification based on natural characteristics and types of economic utilization (forestry and pastoral) for the entire Mongolian area.

Mongolia is one of the largest countries in the world. Its area is $1.564 .116 \mathrm{sq}$. km. Mongolia includes almost all native zones of Inner Asia. It lies in the northern part of Inner Asia. Nearly half of Inner Asian biotic provinces and ecosystems are fully or partly located in Mongolia. One of the prominent features of Mongolian ecosystems is a unique type of the expositional mountain forest-steppe ecosystems.

Long-term investigations carried out by the Joint Russian-Mongolian Complex Biological Expedition of the Russian Academy of Sciences and the Mongolian Academy of Sciences provided a comprehensive assessment and mapping of the modern natural and anthropogenic-natural ecosystems. The principle activities were:

- Complex environmental investigations;

- Inventory of the floristic and faunistic diversity including mapping of ecosystems at different scales;

- Identification of extreme ecological regimes;

- Compilation of ecological data bases;

- Definition of new properties of naturalanthropogenic systems;

- Optimization of the network of natureprotected territories.

According to our analysis, the Mongolian territory has 430 varieties of middle-level ecosystems in total, 348 of which are automorphic and semi-hydromorphic, and 72 are hydromorphic ecosystems 


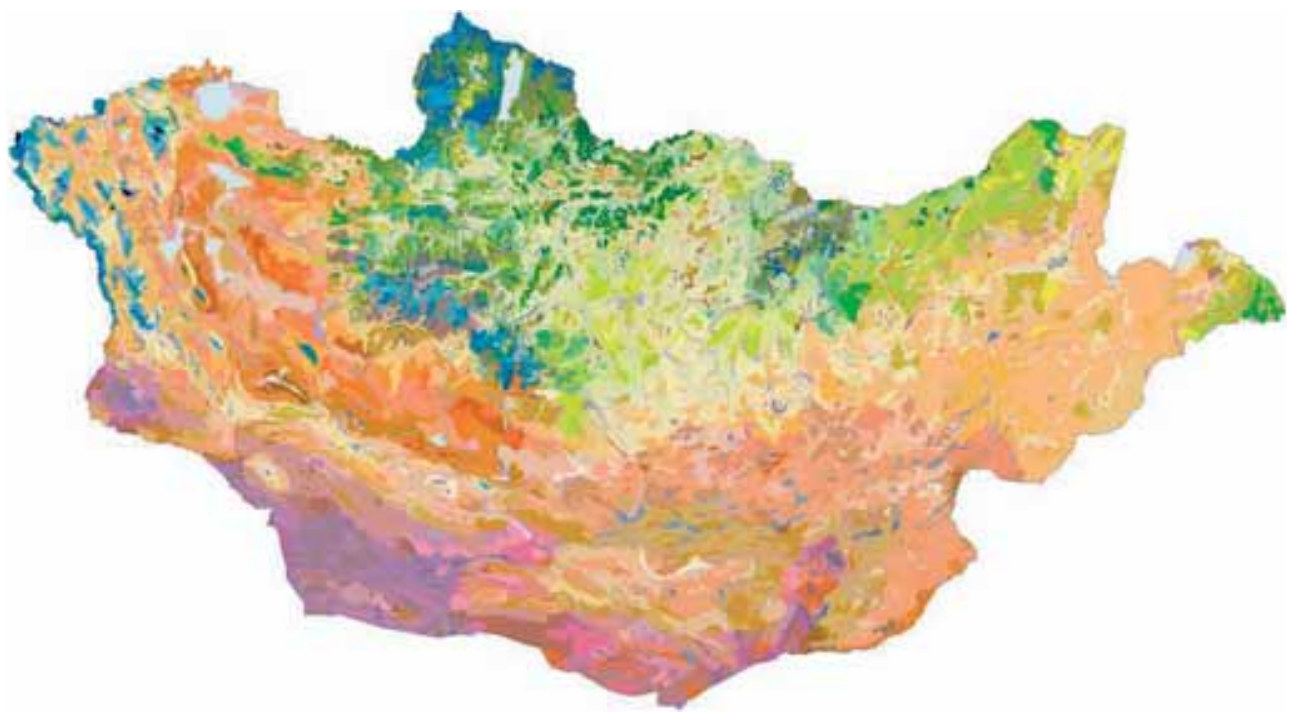

Figure 2. The main types of Mongolian ecosystems.

(See Figures 2 and 3). The total number of contours exceeds 25.000 most of which are arid and semi arid ecosystems (13,310 contours). The average area of one contour is $117,5 \mathrm{sq} . \mathrm{km}$.

Ecosystem diversity in Mongolia is extremely high. The zonal landscapes in their almost $1200 \mathrm{~km}$ north-to-south stretch cover most of the ecosystems of the Eurasian Moderate Belt (from typical mountain taiga to extra arid deserts). Thus, the taiga ecosystems are in direct and broad contact not only with steppes, but with the desert ecosystems too.

Ecosystem diversity depends on geological, geomorphological, and lithological conditions of formation of their ecotopes, as well as on their floristic diversity and their general biodiversity. According to the latest data published by R. V. Kamelin and N. Ulziykhutag [2005], the flora of Mongolia is rather rich and consist of 3.000 different plant species. This fact predetermines a high diversity of phytocenosises in all types of ecosystems.

Mongolian forest ecosystems occupy 119,0 thousand sq. km. The distribution of forests and their differentiation in the dominance of conifers (pine, larch, spruce, fir, and cedar) and parvifoliate (birch, aspen) species in various landscape-ecological conditions are regionally heterogenic. Despite their relatively small area (forest ecosystems occupy $7,6 \%$ of the country's area), they are of exceptional importance to ecological stability and socio-economic development of the country. The forest ecosystems of Mongolia also have global ecological value. They serve as the global ecological barrier against the desertification processes in the Central and Northern Mongolia. Sub-taiga forests (larch and pine) are subject to the most severe impact (sites with high and very high level of disturbance comprise $85,7 \%$ of the area of these ecosystems).

Steppes, semi-deserts, and deserts (most of which are grasslands) occupy the largest area in Mongolia (almost $1.230 .000 \mathrm{sq} . \mathrm{km}$ or more than $90 \%$ of the country's area). Hydromorphic ecosystems along lacustrine hollows and river valleys in arid and semiarid zones of Mongolia experience the greatest disturbance. Such landscapes have a large number of water draw sites that attract livestock. The ecosystems under the moderate and heavy degrees of anthropogenic disturbance make more than $50 \%$ of their combined area. 
1. Automorphic and semi-hydromorphic

(in alluvial, transitional and transition-accumulative landscapes)

\begin{tabular}{|c|c|c|c|c|c|c|c|c|}
\hline \multicolumn{2}{|r|}{ Reitef and surface deposbs } & 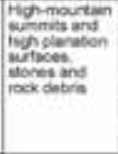 & 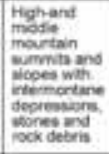 & 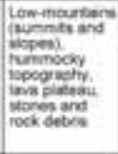 & 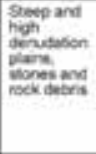 & 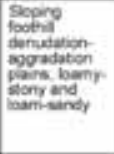 & $\begin{array}{l}\text { Wiogiceolan } \\
\text { sandy plains }\end{array}$ & 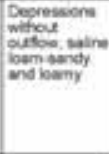 \\
\hline \multicolumn{2}{|c|}{ 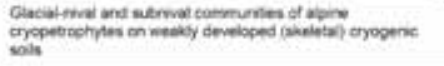 } & & & & & & & \\
\hline \multicolumn{2}{|c|}{ 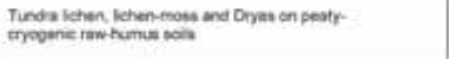 } & & & & & & & \\
\hline \multirow{2}{*}{ 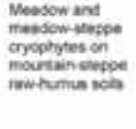 } & 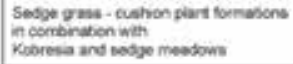 & & & & & & & \\
\hline & 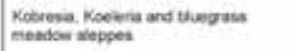 & & & & & & & \\
\hline \multicolumn{9}{|c|}{ 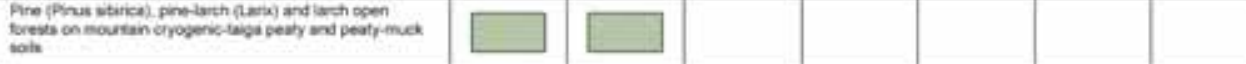 } \\
\hline \multicolumn{9}{|c|}{ 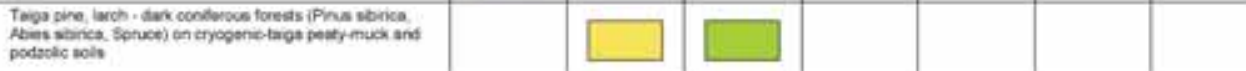 } \\
\hline \multicolumn{9}{|c|}{ 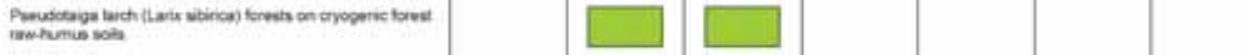 } \\
\hline \multicolumn{9}{|c|}{ 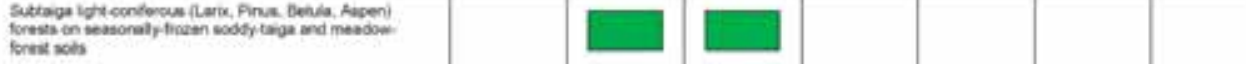 } \\
\hline \multicolumn{9}{|c|}{ 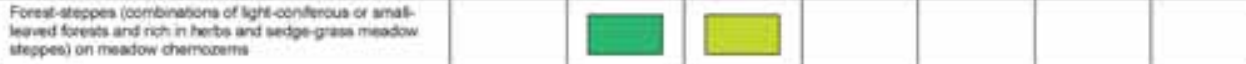 } \\
\hline \multicolumn{9}{|c|}{ 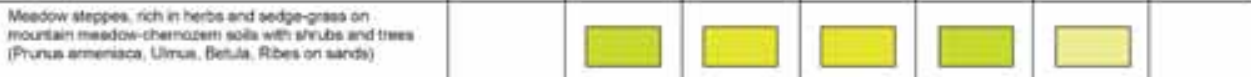 } \\
\hline \multicolumn{9}{|c|}{ 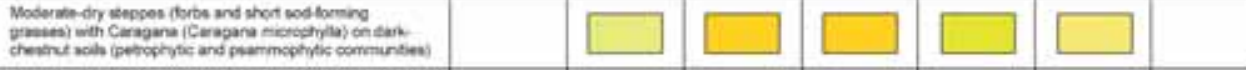 } \\
\hline \multicolumn{9}{|c|}{ 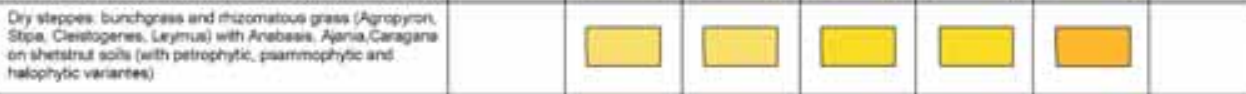 } \\
\hline \multicolumn{9}{|c|}{ 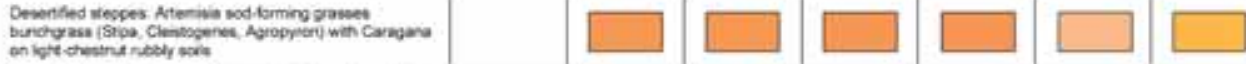 } \\
\hline \multicolumn{9}{|c|}{ 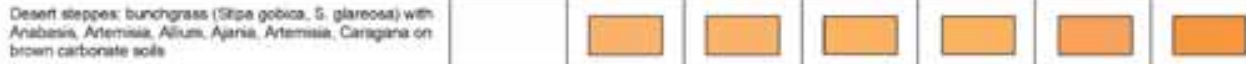 } \\
\hline \multicolumn{9}{|c|}{ 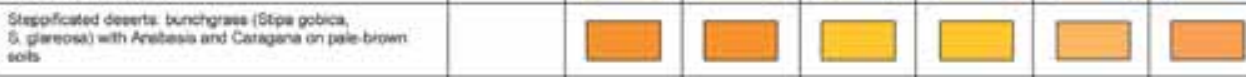 } \\
\hline \multicolumn{9}{|c|}{ 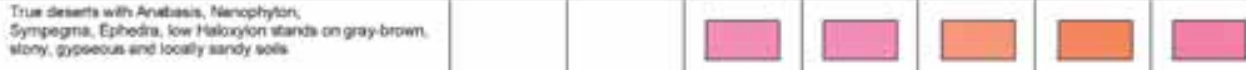 } \\
\hline 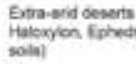 & 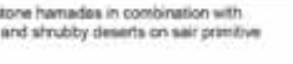 & & & & & & & \\
\hline
\end{tabular}

Figure 3. The main types of Mongolian ecosystems (fragment of the legend).

\section{THE ECO-BIOLOGICAL ASSESSMENT OF THE ECOSYSTEMS CONDITIONS}

The assessment of the ecosystems' status and of the anthropogenic impact on the ecosystems was based on quantitative indices of changes in particular ecosystem components (e.g., vegetation, soils, relief) and on the level of their alteration under the anthropogenic impact. These alteration levels were broken into major groups: absent, slight, moderate, heavy, very heavy, and into transitional categories between these groups [Gunin et al., 1999] (Table 2).

Specific differences in vegetation and its morphology represent reliable criteria for the assessment of anthropogenic impact on the ecosystems. The following parameters were used: changes (compared with the same plant communities of undisturbed plots) in projective cover, structure of grass stand, 
Table 2. The qualitative scale for the assessment of the anthropogenic alteration of the ecosystems.

\begin{tabular}{|l|l|}
\hline \multicolumn{1}{|c|}{ Alteration level } & \multicolumn{1}{|c|}{ State of ecosystems } \\
\hline Absent (I) & $\begin{array}{l}\text { Soil-plant cover is slightly modified; natural regeneration of } \\
\text { slightly modified plots is possible. }\end{array}$ \\
\hline Slight (II) & $\begin{array}{l}\text { Satisfactory, the modification of ecosystems is observed where } \\
\text { cattle are grazed; frequently, natural regeneration of the majority } \\
\text { of modified plots is possible. }\end{array}$ \\
\hline Moderate (III) & $\begin{array}{l}\text { Moderate, there are more modified plots than at the preceding } \\
\text { stage; natural regeneration is possible but difficult. }\end{array}$ \\
\hline From moderate to heavy & $\begin{array}{l}\text { Moderate, occasionally poor at forest plots; forest regeneration } \\
\text { feasible with temporary bans on grazing, regulation of tree felling. }\end{array}$ \\
\hline Heavy (IV) & $\begin{array}{l}\text { Poor, soil-plant cover is occasionally modified irreversibly and } \\
\text { natural regeneration is extremely difficult. }\end{array}$ \\
\hline From heavy to very heavy & $\begin{array}{l}\text { Poor, occasionally very poor; natural ecosystems have been } \\
\text { virtually destroyed and natural regeneration is frequently } \\
\text { impossible. }\end{array}$ \\
\hline Very heavy (V) & $\begin{array}{l}\text { Very poor, natural ecosystems have been replaced by man-made, } \\
\text { or the plots represent an industrial badland (spoils, dirt piles, } \\
\text { quarries, etc.); natural regeneration is impossible. }\end{array}$ \\
\hline
\end{tabular}

floristic composition, height of grass stands, sod thickness, weed species presence, and plant species abundance and viability. Morphological characteristics of soil profiles and agrochemical indices in the upper soil horizons were also taken into account.

We analyzed anthropogenic impact on the ecosystems of the alteration levels III, IV, and V. The anthropogenic factors can be divided into two groups: (1) factors leading to the destruction of natural vegetation and the disruption of natural links and the initial ecotype formation and (2) factors that allow indigenous vegetation and the ecotypes to largely recover after anthropogenic disturbances (immediately or in the course of successional replacement). The pattern of spatial distribution of disturbances is shown in Table 3.

The largest area in Mongolian ecosystems is occupied by rangelands, 23,3\% of which have moderate level of alteration (level III) and 3,6\% have heavy to very heavy level of alteration (levels IV and $\mathrm{V}$ ). The forest ecosystems exposed to cuttings and anthropogenic fires comprise over 51,5\%

Table 3. The relationship between the types of anthropogenic impact and the levels of ecosystem alterations in Mongolia

\begin{tabular}{|l|c|c|c|c|c|}
\hline \multirow{2}{*}{$\begin{array}{c}\text { Type of anthropogenic } \\
\text { impact }\end{array}$} & \multicolumn{5}{|c|}{ Degradation extent by the levels of alteration (\%) } \\
\cline { 2 - 6 } & I & II & III & IV & V \\
\hline Overgrazing & 20,23 & 52,89 & 23,26 & 3,55 & 0,07 \\
Forest cutting & 56,80 & 15,23 & 9,39 & 6,39 & 12,19 \\
Forest fires & 47,21 & 29,29 & 13,77 & 0,93 & 8,80 \\
Land plowing & 0,00 & 0,00 & 0,00 & 54,20 & 45,80 \\
Urbanization & 0,00 & 0,00 & 0,00 & 91,13 & 8,87 \\
Complex effect & 22,25 & 25,09 & 35,51 & 12,76 & 4,39 \\
\hline
\end{tabular}


of all forest ecosystems; the impacted areas are concentrated in the northern parts of Mongolia. The share of cultivated lands is very small $(0,75 \%$ of the country's territory) and is currently represented by heavily degraded fallow lands (54, $2 \%$ and 45,8 \% of degradation levels IV and $V$, respectively). Other ecosystems (including hydromorphic ecosystems under integrated impact, ecosystems under technogenic impact, etc.) account for no more than $3,57 \%$ of all lands, with approximately one-half in heavily altered categories.

\section{THE IDENTIFICATION OF DEGRADATION/ DESERTIFICATION PROCESSES IN SUCCESSIONS OF PLANT COVER}

Analyses of our own surveys performed over the last decade as well as analyses of the results obtained by other researchers who previously conducted geo-botanical surveys in Mongolia provided multi-temporal descriptions of the vegetation at the same plots. The sites were located mainly in the areas of stationary integrated observations at selected testing plots of the sub meridian transect Ulan-Ude - Ulaanbaatar - Hohhot. The analysis of the multi-temporal data allowed the identification and assessment of various degradation processes in the plant cover.

The categories of heavy and very heavy anthropogenic alterations of the natural environment contained five groups of hazardous degradation processes:(1) rangeland overgrowth with shrubs, (2) deforestation of forest-steppe ecosystems, (3) desertification of ecosystems on light soils, (4) depletion of ecosystems of hydromorphic landscapes, and (5) narcotization of agrocenoses in altered ecosystems [Gunin, Bazha, 2003].

Overgrowth of Rangeland Steppe Ecosystems with Shrubs. An important feature of the ecosystems studied, as well as of Asian steppes in general, was their overgrowth with various types of shrubs and dwarf semishrubs of the genera Caragana, Artemisia, Spiraea, Armeniaca, Amygdalus, Dasiphora, etc.
It appeared that the participation of shrubs and dwarf semi-shrubs in the communities of the Eastern-Asian sector of the steppe zone increased with the increase of the anthropogenic pressure on the rangelands. Several species played significant role in degraded rangelands, including shrubs Caragana microphylla, Caragana pygmaea and dwarf semi-shrubs Artemisia frigida, Thymus gobicu,s and Potentilla bifurca; their abundance was directly proportional to a degree of the rangeland alteration.

Deforestation of Larch and Pine Forest Ecosystems. To investigate the process of deforestation of larch and pine forests, complete geobotanical and taxonomic descriptions of tree and shrub species were obtained. Tree evaluation included measurements of their height and trunk diameters. Shrub measurements included the count of trunks, height and diameter of the shrubs, and measurements of aboveground phytomass.

A complete succession series had 5 major stages: I - indigenous forests (Pinus silvestris, Larix sibirica); II - small leaved forests with a mixture of indigenous species (Betula platyphylla, Populus tremula, Larix sibirica, Pinus silvestris); III - small leaved forests without contribution of indigenous species, including undergrowth or thickets of shrubs with dead trees, or without undergrowth of arborous species (Betula platyphylla, B. fusca, Populus tremula, Cotoneaster melanocarpa and Salix sp.); IV - thickets of shrubs without involvement of any trees (Cotoneaster melanocarpa, Spiraea aquilegifolia, Amygdalus pedunculata, Armeniaca sibirica, Betula fusca, and Salix sp.); and V - steppe stage (Carex korshinskyi and C. pediformis). Desertification of Ecosystems with Soils of Light Granulometric Composition. One problem of desertification in Mongolia is associated with natural predisposition of fragile environment to degradation processes resulting from anthropogenic impact. We define the desertification process as the process when more arid elements penetrate into degraded ecosystems. Such elements included: (1) 
the formation of barchan-like forms of relief on altered plots with sand soils, (2) the development of salinization processes in forest-steppes resulting from water erosion of salt-containing waste piles, and (3) the incorporation of dry steppe species typical of deserts into altered phytocenoses. The first species to advance through the disturbed habitats into the neighboring zones were pest anthropophillic species (Caragana bungei, C. spinosa, Ephedra sinica, Corispermum mongolicum, Agriophyllum pungens, Peganum harmala, P. nigellastrum, etc.) characteristic of sandy or salinized habitats.

Depletion of Rangelands of the Hydromorphic Landscapes. The rangelands of the hydromorphic landscapes are common in the river valleys and lake depressions. The major anthropogenic factors of long-term dynamics of plant communities are the concentration of the human population and livestock and unregulated human traffic. The phytocenoses of alteration stages III and IV in meadow steppe sod soils consisted of meso- and xeromorphic species Carex duriuscula, Artemisia frigida, A. commutata, A. laciniata, and $A$. adamsii. At the final stage of the succession series, iris species (Iris lactea, I. bungei) became the edifier perennial species that grew virtually everywhere (e.g., on the terraces and floodplains of meadow communities) and replaced initially different dominant species.

Narcotization of Agrocenoses in Fallow Lands and Highly Modified Ecosystems. We regard the current distribution of the Cannabis species in such a vast region as the north and central parts of Mongolia as the manifestation of a syngenetic succession. The distribution of Cannabis sp. is primarily promoted by their biological properties. Environment, i.e., the presence of conditions providing for the germination of seeds and seedlings' development is also very important. Furthermore, Cannabis has a high environment forming capacity, successfully competing with species that form phytocenoses into which it is incorporating.
In the ecosystems studied, it frequently formed monocenoses from tall $(1,5 \mathrm{~m}$ and higher) above ground phytomass with large mass providing up to 2,5 to 3,0 tons/ha of biomass in ruderal plant communities.

\section{THE MAIN RECOMMENDATIONS FOR CONSERVING MONGOLIAN ECOSYSTEMS}

Mongolia is an area of many unique natural objects, including residual populations of many endangered animal species. This fact stipulates a rather small disturbance of nature in the region as a whole: human population density remains still low within a large part of the territory; traditional ways of nature management prevail.

It is critical to enhance the status and implementation of regulations, boundaries, and goals for legally protected areas.

Specific efforts should be directed towards: i) defining the network of reserves and national parks; ii) enacting guidelines for cultivation of disturbed lands; and iii) establishing and evaluating ecologically and economically justified systems of ecosystem management. Collectively, these measures would promote conservation and recovery of plants, animals, ecosystems and plant regeneration successions while reducing the rate of vegetation degradation across the entire Mongolia.

The comprehensive evaluation of negative changes occurring in the natural habitats has enabled the revision of the state policy for the organization of an optimal network of wild life reserves aimed at conservation of floristic and faunistic diversity. In 1993, under the initiative of the Ministry for Nature and Environment of Mongolia and under the support of international organizations within the framework of the UNDP-GEF project Biodiversity Conservation and Sustainable Livelihood Options in the Grasslands of Eastern Mongolia the long-term plan for the organization of protected areas (PAs) (Component B. Conservation Areas/Wildlife, 1993) was developed. This plan provided for 
the expansion of the area of the PAs (from $5,5 \%$ to $25,0 \%$ ) and for the increase in their total number (from 21 to 60), including the organization of 12 transnational PAs (Mongolian - Russian and Mongolian Chinese) [Gunin, 1993]. During the following decade(1994-2003), this planwassuccessfully realized in its significant part. Today, the state PAs in Mongolia include 48 natural reserves of different ranks (reservations, national parks, and natural reserves) which occupy 20,5 million ha $(13,1 \%$ of the country's area). Despite significant progress in the organization of a unique, to Asia, Mongolian PA system, the spatial distribution of PAs requires further development. For example, the dry steppes and semi-desert subzones in the central and eastern parts of Mongolia are least presented in the state PAs. Thus, they are completely absent in the ValleyLacustrine region of the Central - Asian region. Only a small areas are occupied by the PAs in the Eastern Khalkha district of the Daur Mongolian region (0,81 \% of the area) and in the Central Khalkha district of the Central Mongolian region (0,80 \%). The percentage of area of the PAs in the Middle Gobi district of the Central Asian region is also relatively small (only $4,1 \%$ ), which is insufficient too. It is important to note, that the share of land under all PAs in the country is very small in general and that the PAs have currently a low nature protection status (Natural Reserves or Natural Monuments).

These conclusions and recommendations are of primary importance in achieving conservation and management of the landscapes and vegetation of Mongolia that will sustain the traditional grazing-based economic culture in Mongolia.

\section{REFERENCES}

1. Gunin P.D. (1993) Component B. Conservation Areas/Wildlife. Final Report. Ulaanbaatar. November. 66 p. (In English).

2. Gunin P.D., Bazha S.N. (2003) Ecological assessment of degradation processes in the Northern part of Baikal Basin. In: Conserving Biodiversity in Arid Ecosystems. KAP. Chapter 12. pp. 157-177. (In English).

3. Gunin P., Bazha S. (2004) Prospects and problems of development transboundary protected areas in Inner Asia // Proceedings of the All-Russian Sci. Conf., Ulan-Ude: Buryat Center of Siberian Branch RAS. p. 7-9. (In Russian).

4. Gunin, P.D. \& Vostokova, E.A. (Eds). (1995). The map "Ecosystems of Mongolia", scale 1: 1000 000. 15 sheets. Moscow. (In English).

5. Gunin P., Vostokova E., Dorofeyuk N., Tarasov P., Black C. (1999) Vegetation Dynamics of Mongolia. Kluwer Academic Publishers. Dordrecht/Boston/London. 225 p. (In English).

6. Gunin P.D., Vostokova E.A., Matyushkin E.N. (1998) Protection of Ecosystems of Inner Asia. Moscow. Nauka. Vol XL. 219 p. (In Russian). 
7. Kamelin R.V., Ulziykhutag N. (2005) New data on the Mongolian flora of vascular plants and perspectives of the future investigations // Proceedings of Int. Conf. "Ecosystems of Mongolia". Ulaanbaatar. Bembi San P.H. pp. 104-106. (In Russian).

8. Kharin N.G., Tateishi R. (2004) Map of degradation of the drylands of Asia // Arid Ecosystems. Vol. 10. N 24-25. pp. 17-28. (In English).

9. Rachkovskaya E.I., Volkova E.A., Evstifeev Yu.G. (2007) Central Asia as a geographical region and natural regionalization // Ecosystems of the Inner Asia: Issues of Research and Conservation.Moscow. pp. 22-33. (In Russian).

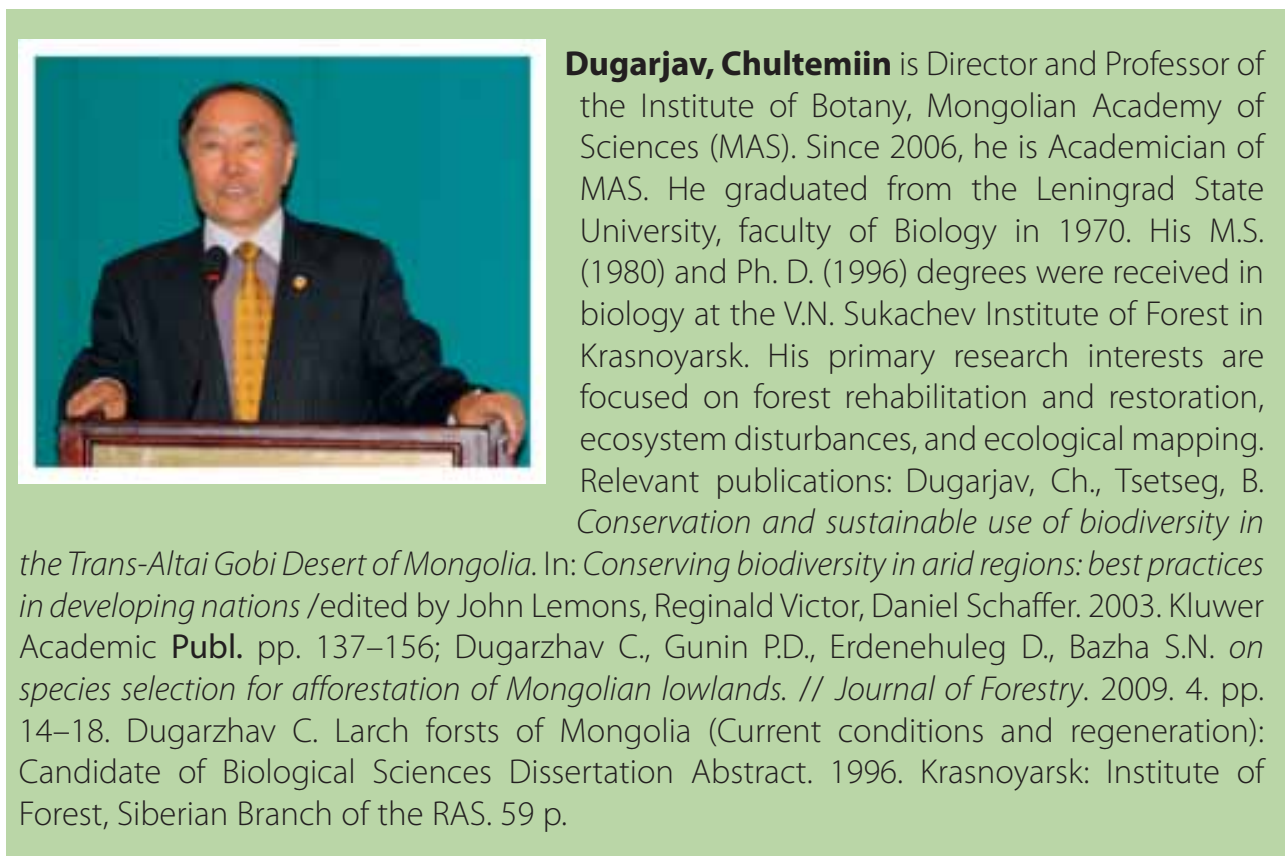

Peter D. Gunin, is Head of laboratory of Arid Territories Ecology, IEE RAS (since 1994), He is Dr. Biol. Sc. and Professor. During the last 25 years, he has been studying ecosystems in Mongolia. He is Head of the Russian Component of the Joint Russian-Mongolian Complex Biological Expedition (since 1989) - the world biggest biological expedition on ecosystem studies. For over 40 years, he has been involved in largescale integrated eco-biological research, including ecosystem protection and conservation, degradation processes in plant-soil cover, ecosystem rehabilitation, and ecological mapping. He is the author of more than 290 publications. Relevant publications: Ecology of desertification processes in arid ecosystems. 1990. VASHNIL, Moscow, 354 p.; Methodological recommendations on assessment and mapping of the contemporary ecosystems

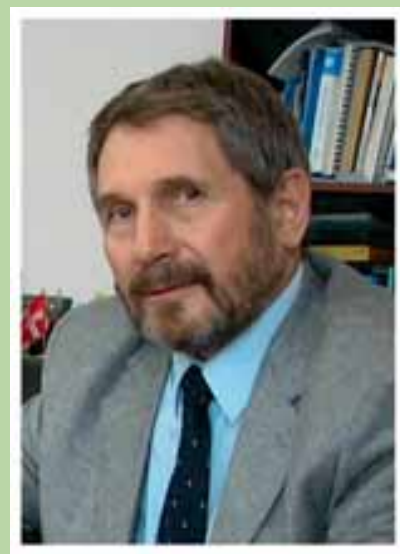
of the MPR., 1989. GUGK of the MPR, Moscow, Ulaanbaatar, 60 pp. (with E.V. Vostokova); Ecosystems of Mongolia. Map at a scale 1: 1,000,000. 1995. Moscow (with E.V. Vostokova); Vegetation Dynamics of Mongolia. 1999. Kluwer AP. 240 pp. 


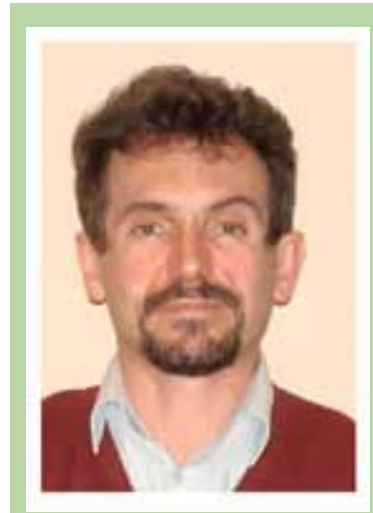

Sergey N. Bazha graduated in economics from the University of Agricultural Sciences, Hungary, in 1989. In 1993, he finished postgraduate studies at the Institute of Economics, Moscow. In March of 1998, he became Research Assistant and in 2002 Senior Research Associate at the A.N. Severtsov Institute for Ecology and Evolution of the RAS, Moscow, where he received his Ph.D. in ecology in 2002. His primary research interests are focused on ecological risks, environmental pollution, plant-soil degradation, and ecological mapping. Main publications: Gunin P.D., A.K. Evdokimova, S.N. Bazha, and M. Saandar. Social and Ecological Problems of Mongolian Ethnic Community in Urbanized Territories. 2003. Ulaanbaatar-Moscow. Rosselkhozacademic Publ. 96 p.; Gunin, P.D. and S.N. Bazha. Ecological Assessment of Degradation Processes in the Mongolian Part of the Baikal Basin / Monograf Conserving Biodiversity in Arid Regions. Kluwer Acad. Publ. 2003. p. 157-177; Gunin P., E. Vostokova, S. Bazha, A. Prischepa, I. Miklyaeva, R. Tateishi, and Ch. Dugarjav. Present-Day Ecosystems of the Selenga River Basin and Factors of their Destabilization. CEReS, Chiba University. Japan. 2006. $139 \mathrm{p}$

Saandar, Mijiddorj was born in the Choibalsan province of Mongolia in 1952. He is President of Monmap Itd. and Head of the Geolnformation Technology Center. He graduated from the Moscow Survey Engineering Institute. His Ph. D. degree in Aerial Survey Engineering (1985) was received from the Moscow Central Research Institute of Survey Engineering. His scientific interests include surveying and mapping using aerial and satellite images, photogrammetry, and ecological mapping. Dr. Saandar is President of the Mongolian Society of Photogrammetry and Remote Sensing, and a member of the Asian Association on Remote Sensing. He published approcimately 45 scientific papers. Relevant publications: A Multipurpose ecological mapping and evaluation of Mongolian nature based on remote sensing and ground data. 1995. (with P.Gunin). In: Proc.16 $6^{\text {th }}$ Asian Conference on Remote Sensing, Thailand; Late Cenozoic transgression in southwestern Mongolia and the Gobi Altai-Tien Shan connection". 1995. (with W. Cunningham, B. Windley, D.Dorjnamjaa, and J. Badamgarov). Earth and Planetary Science Letters. 140 (1996) 67-81, Elsevier; Ecosystems of Mongolia, Moscow, 1995, Russian-Mongolian Complex Biological Expedition, 16 sheets, Scale 1:1 000 000; A Structural transect across the Mongolian Western Altai: Active transgressional mountain building in Central Asia. 1996. Tectonics, 15(1): 142-156. 